\title{
LIVROS MIGRANTES - UMA GEOGRAFIA LITERÁRIA DO LIVRO YIDDISH NO BRASIL
}

\author{
Migrant books - a literary geography of yiddish books in Brazil
}

Henri Acselrad*

\begin{abstract}
Resumo. O presente texto reconstitui a geografia literária dos livros em língua yiddish traçada pela imigração judaica da Europa do Leste para o Rio de Janeiro, a partir do início do século XX. Examinando as marcas da trajetória espacial destes livros migrantes, o artigo procura, a partir da consulta ao acervo composto ao longo de mais de cem anos pela Biblioteca Scholem Aleichem do Rio de Janeiro, descrever a espacialidade dos fluxos culturais expressos nos livros e entender a sequência de ações que deu vida extraterritorial a tais objetos, exprimindo os conteúdos intelectuais compartilhados por uma geração que militou na convergência entre luta social e luta linguística.
\end{abstract}

Palavras-chave: imigração judaica; bibliotecas; geografia literária; livro yiddish; objetos migrantes.

\begin{abstract}
The text discusses the literary geography of yiddish book dressed by jewish immigrants from Easterm Europe to Rio de Janeiro, in the beginings of the XXth century. Looking at the traces of spatial trajectory of this migrant books, the text intends to describe, through examining the Rio de Janeiro Scholem Aleichem Library collection, the spatial cultural flows expressed in those books, trying to understand the meaning of actions that gave extraterritorial life to these objects, which intelectual contents has been shared by a generation that act for the convergence between social and linguistic struggle.
\end{abstract}

Keywords: jewish immigration; libraries; literary geography; yiddish books; migrant objects.

\begin{abstract}
Não é por acaso que esta pequena biblioteca, como uma estratificação geológica, foi sendo disposta ao longo de dezenas de anos (...) Vocês não gostariam de conhecer a chave desta época, o livro que ardeu ao contato das mãos, que por nada no mundo queria morrer e que jazia como vivo? O livro cujas páginas amarelaram precocemente, por que foram muito lidos ou porque estiveram expostos ao sol nos bancos das varandas?

(Ossip Mandelstam, La Bibliothèque, in Le Bruit du temps, Christian Bourgois Ed., Paris, [1925], 2006)
\end{abstract}

IPPUR/UFRJ e pesquisador do CNPq. Rio de Janeiro, RJ, Brasil. E-mail: hacsel@uol.com.br. Orcid: https://orcid.org/0000-0001-5774-5220. 
Ao longo de seus deslocamentos ${ }^{1}$, as comunidades migrantes ou em diáspora inscrevem suas formas de expressão cultural e espiritual também em objetos materiais. Estes objetos migrantes desempenham importante papel na conexão de grupos humanos e indivíduos através do tempo, de territórios e culturas. Eles auxiliam estes grupos a construir um sentido de pertencimento em contextos antes desconhecidos, permitindo estabelecer conexões entre seu passado e seus novos espaços de vida. Eles incorporam, assim, uma espacialidade através da qual carregam as marcas dos lugares em que foram produzidos e onde circularam, de sua concepção e manuseio, das formas técnicas e estéticas de sua construção e disposição nos locais de reinserção dos migrantes.

Uma série de pesquisas tem se dedicado a discutir os objetos migrantes como portadores das "marcas materiais e simbólicas dos fluxos migratórios" ${ }^{2}$. Essas iniciativas buscam tratá-los como componentes de um domínio simbólico próprio à vida na imigração, permitindo pensar os modos como os sujeitos em deslocamento se reconstituem a partir de e com os objetos. Na construção da figura do migrante, o deslocamento condiciona as formas de inscrição dos afetos em torno a objetos, alguns deles - como é o caso dos livros - tornando-se uma espécie de objetos-memória, sendo vistos como relíquias submetidas a temporalidades e estatutos particulares, pontos de ancoragem que permitem reagenciamentos criativos e reinscrição nos espaços de chegada. É também na condição de objetos-sujeitos que eles podem falar por aqueles que - como é o caso dos milhões de falantes da língua yiddish mortos pela barbárie nazista - perderam a condição de falar ${ }^{3}$. Grande parte da vida dos povos em exílio é dedicada a compensar suas perdas pela criação de novos mundos em seus espaços de acolhida, com frequência através, entre outras, de atividades intelectuais e da criação de bibliotecas (Said, 2003, p. 54-57).

Um processo desta ordem ocorreu no Rio de Janeiro, quando, no ano de 1915, um grupo de imigrantes judeus originários da Polônia, Bessarábia e Ucrânia fundou a Biblioteca Popular Scholem Aleichem. As atividades político-culturais que os reuniam tinham por centro a biblioteca; a identidade judaica de seus membros se apoiava fortemente nos livros e tinha por veículo a língua yiddish,

O autor agradece a Carlos Acselrad e Abrão Rumschinky pelo apoio dado à tradução de textos em yiddish.

2 Diversos seminários e coletâneas têm sido dedicados a discutir temas como "objetos migrantes e transmissão cultural", "a construção da figura do exilado por objetos no espaço narrativo", "objetos na migração e objetos no exílio" a exemplo de Maruška Svašek (ed.). Moving Subjects, Moving Objects: Transnationalism, Cultural Production and Emotions da série Material Mediations: People and Things in a World of Movement, NY, Berghahn, 2014 e do número especial da revista Géographies et Cultures, de 2014, sobre a Geografia dos objetos.

3 A língua yiddish surgiu no século XI na região do Reno, mesclando ao médio alto alemão elementos românicos e eslavos, assim como uma forte proporção de termos importados do hebraico. Cf. R. Robin. L'Amour du Yiddish. Ed. du Sorbier, Paris, 1984, p. 59. Os judeus que migraram para a França, Alemanha, Rússia, e Europa do Leste entre os séculos X e XIX ficaram conhecidos como "ashkenazim" (termo hebraico medieval para "alemão") enquanto os judeus da Espanha ficaram conhecidos como "sefaradim" (palavra hebraica para "espanhol"). 
falada originariamente pelos judeus ashkenazim da Europa. Constituído ao longo de mais de cem anos, o acervo desta Biblioteca exprime as interrogações de parte da geração de imigrantes judeus chegados ao Brasil nas primeiras décadas do século XX, seus volumes constituindo o suporte material de uma produção cultural que refletiu e alimentou os debates políticos, a curiosidade intelectual e a vida literária deste grupo.

O presente texto pretende explorar a "estratificação geológica" da referida biblioteca, examinando as marcas do trajeto destes livros migrantes que percorreram longas distâncias em paralelo ao deslocamento de seus leitores. O exame de tais marcas pode nos ajudar a entender a "biografia" destes objetos migrantes (Appadurai, 2008, p. 17). Recorremos, para tanto, a uma modalidade de geografia da literatura que não se ocupa da localização geográfica de autores e gêneros (Döring, 2012), mas da espacialidade dos fluxos culturais expressos nos livros enquanto objetos. Com este fim, foram realizadas consultas a documentos que traçam a história da Biblioteca Scholem Aleichem, bem como ao conteúdo de seu acervo, atentando para a multiplicidade de carimbos que indicam, em suas páginas, os trajetos que foram percorridos por seus livros

\section{Um território cultural em rede}

Ao partirem de seus locais de origem a partir do final do século XIX, os imigrantes judeus da Europa do Leste deixaram para trás o universo de crise que o desenvolvimento do capitalismo na Rússia e na Polônia havia levado ao shtet $l^{4}$ judaico. A vida tradicional destas pequenas aldeias se desfez sob os efeitos da urbanização, da crise do artesanato e do crescimento da emigração após os pogroms do período $1881-1903^{5}$. A integração daqueles países à dinâmica dos capitais europeus desestruturou as formas sociais que até então haviam dado estabilidade ao isolamento dos shtetls. Incapaz de fazer frente à competição da grande indústria, o artesanato judaico se desarticulou, sem que o capital industrial se dispusesse a absorvê-lo significativamente (Pinsky, 1997). No plano político e ideológico, as estruturas subjetivas que reproduziam até então o judaísmo tradicional foram seriamente atingidas. Com a institucionalização da miséria e o recrudescimento do antissemitismo estimulado por governos, iniciou-se um processo de emigração em massa: cerca de seiscentos mil judeus da Europa do Leste e da Rússia emigraram entre 1880 e 1900.

Paralelamente à crise, desenvolvia-se também, à época, um processo de redefinição da identidade judaica, envolvendo suas dimensões culturais, políticas,

\footnotetext{
4 Shtetl é o nome atribuído às pequenas aldeias com grande presença judaica nos países da Europa do Leste e da Zona de Residência do Império Russo antes do Holocausto.

5 A palavra russa "pogrom" designa ações coletivas violentas contra pessoas, com a destruição simultânea de seus ambientes (casas, negócios, centros religiosos). Historicamente, o termo tem sido usado para denominar atos em massa de violência, espontânea ou premeditada, contra judeus e outras minorias étnicas da Europa.
} 
espirituais e territoriais. Uma cultura yiddish letrada tomava forma. A crescente difusão de um universalismo judaico elevava o yiddish ao status de língua literária. A expressão cotidiana do yiddishkeit - universo de uma língua que, como assinalou Bashevis Singer (1984, p. 17), "nunca foi falada por militares, pela polícia, por gente de poder e de influência", passou a integrar o campo da literatura e da produção cultural. Em todo o território linguístico do judaísmo europeu do Leste e da zona de residência na Rússia, multiplicaram-se bibliotecas em língua yiddish. Instituições deste tipo foram, por sua vez, recriadas pelas comunidades judaicas formadas por imigrantes em seus países de destino, como instrumentos de agregação social e preservação cultural. Se, por um lado, as fronteiras nacionais não são um obstáculo para o trânsito de livros, revistas e impressos em geral, a própria literatura yiddish não se constituiu no interior de fronteiras nacionais, mas, sim, através de um conjunto de trocas entre centros culturais judaicos situados em diferentes países e continentes.

No Brasil, a maior onda de imigração judaica verificou-se entre 1920 e 1939, quando chegaram ao país cerca de 53 mil pessoas, 56\% da imigração judaica total vinda para o Brasil entre 1872 e 1972. Segundo dados do Censo, a população autodeclarada judaica era de 56 mil pessoas em 1940 (Decol, 2001, p. 153$)^{6}$. Migraram judeus e migraram também seus livros. Chegados ao Brasil, estes volumes receberam as marcas do deslocamento de seus leitores através do país, bem como da tendência destes leitores ao desenvolvimento de uma vida associativa. Carimbos de diferentes bibliotecas justapõem-se sobre os mesmos livros, mostrando que eles percorreram distintas comunidades até serem reunidos na Biblioteca Scholem Aleichem, objeto específico do presente texto ${ }^{7}$. Seu acervo contém obras editadas, desde o final do século XIX, nas cidades europeias de Vilna, Varsóvia, Bialystok, Kharkov, Lemberg, Riga, Minsk, Petersburg, Ekaterinoslav, Viena e Berlim, assim como em Moscou, Buenos Aires, Nova lorque e Rio de Janeiro. No cruzamento desses trajetos, diferentes camadas de memória foram sendo depositadas, constituindo uma coleção de obras que serviu, para os imigrantes, ao mesmo tempo, de "farol e porto" para a afirmação de sua identidade (Chartier, 2003, p. 26).

Que processos deram origem aos fluxos culturais inscritos nestes livros migrantes? Em fins do século XIX, um intenso debate se instaurou, notadamente na Europa, a respeito da espacialidade da cultura judaica. O movimento sionista propunha a emigração para a constituição de uma nova unidade espacial - estatal.

\footnotetext{
${ }_{6}$ Outras fontes registram um total de 32.521 indivíduos chegados ao Brasil entre 1925 e 1935 (Lesser, 1994, p. 173).

7 Provenientes de fora do estado do Rio de Janeiro há livros com carimbos de bibliotecas judaicas do Vale do Paraíba, Taubaté, Campos, Juiz de Fora, São Paulo e Belo Horizonte. Da cidade do Rio de Janeiro e proximidades vieram livros procedentes de Niterói, Nilópolis, subúrbios da Leopoldina, e Madureira. Alguns volumes possuem carimbos de bibliotecas situadas nas próprias cidades de origem dos imigrantes, como Pietrkow, Kalish e Ostrowiecz, na Polônia.
} 
O BUND ${ }^{8}$ propunha conciliar o desenvolvimento de uma consciência nacional com uma consciência de classe: nem assimilação, nem emigração, mas a luta no local, juntamente com os trabalhadores dos outros agrupamentos nacionais que viviam na Rússia (Ertel, 2003, p. 47). Grupos próximos aos partidos comunistas, críticos ao sionismo, propunham uma "desespacialização" da identidade judaica, supondo, por sua vez, que o esforço de afirmação cultural poderia vir a obscurecer as diferenças de classe ${ }^{9}$. A perspectiva extra-estatal de um território cultural era pensada, por alguns intelectuais, como requerendo um confronto com o Estado. Tal como o expressou I. L. Peretz ${ }^{10}$ na Conferência de Czernovitz sobre a língua yiddish, em 1908: "povos fracos e oprimidos despertam e lutam por sua língua, por sua singularidade, contra o Estado, e nós, os mais fracos de todos, cerramos fileiras!"11. A realização desta Conferência foi marcante para a maturação do processo de construção de uma consciência nacional associada ao yiddish (Weiser, Fogel, 2010).

Contrariando os que pensavam que a insistência no papel libertário do território cultural obscureceria as diferenças de classe na sociedade judaica, verificou-se uma espécie de analogia entre um grupo social e uma língua, laço de identificação que deslocou progressivamente o eixo da religião. O yiddish tornava-se um dos objetos maiores deste combate e o processo de secularização tomou a forma de uma politização, fazendo convergir a luta social e a luta linguística (Ertel, 2003, p. 31).

A rápida elevação do nível educacional da população judaica no começo do século XX levou a uma secularização crescente da vida judaica. Como sustentou o escritor Ossip Mandelstam, "no ghetto esclarecido, os interesses religiosos foram completamente aniquilados. A filosofia das Luzes transformou-se em um panteísmo talmúdico alambicado: em lugar do Talmud, lê-se Schiller, Spinoza e Rousseau - os ideais filosóficos do século XVIII" (Mandelstam, 2006, p. 50).

$\mathrm{Na}$ fronteira entre o político e o cultural, entre atividades legais e ilegais, foram se multiplicando, na Europa do Leste, as bibliotecas em língua yiddish. Eis o relato-testemunho de Motel Poliansky, sobre a atividade cultural judaica desenvolvida em fins dos anos 1920, em Securon, na Bessarábia:

8 O BUND foi formalmente criado em outubro de 1897, em Vilna. Marcando a posição fundante deste agrupamento, Arkadi Kremer afirmava: "o proletariado judeu participará do partido russo geral, mas deverá fazê-lo de forma organizada e não ao nível de indivíduos ou de pequenos grupos" (Pinsky, 1997, p. 101).

9 Contra a perspectiva de um território cultural, os comunistas "não concordavam em erigir uma instituição passível de servir, a pretexto da comunidade linguística e cultural, de biombo para ocultar a luta de classes no âmbito judeu" (Guinsburg, 1996, p. 161).

10 Itzhak Leibush Peretz (1852-1915), juntamente com Scholem Aleichem e Mendele Mokher Sforim forma a tríade clássica da primeira geração de autores da literatura em língua yiddish, responsáveis pela estética moderna do universo judaico ashkenazita.

11 I.L Peretz, Efenung-rede, in Di Erschte lidische Schprackh-konferentz, apud Guinsburg, J. Aventuras de uma língua errante. Ed. Perspectiva, São Paulo, 1996, p. 160. 
Certa vez, já confiando em mim, Idel me introduziu na cozinha e me mostrou um pequeno armário que ficava lá no canto, do lado de lá do balcão. Eu pensava que esse armário, como o de todos os sapateiros, ficava cheio de sapatos, couros, tachas e material de sapataria em geral. Idel abriu a porta e eu vi livros. E que livros! Gorki, Romain Rolland, Peretz, Scholem Aleichem, uma fortuna. Havia livros não encontrados em nenhuma outra biblioteca, livros expressamente proibidos. Para nós, o armário da cozinha era um verdadeiro tesouro. Os livros eram passados de um a outro, mas poucos sabiam sua procedência. (Poliansky, 1978)

Em que pese língua yiddish existir, como vimos, há séculos, apenas os anos situados entre 1880 e 1940 foram bons para as bibliotecas de livros em yiddish. No início dos anos 1900, muitas bibliotecas foram sendo criadas pelas comunidades do Yiddishland ${ }^{12}$, algumas delas ligadas ao movimento operário nascente. O boom das publicações em yiddish coincidiu com o período de relativa estabilidade da presença judaica em certas partes da Europa. Umas poucas coleções privadas foram integradas a bibliotecas públicas, como foi o caso em Amsterdam e Frankfurt, cidades, à época, mais receptivas aos judeus.

Ao longo dos anos 1930, as bibliotecas de língua yiddish na Europa do Leste expandiram-se exponencialmente. Em toda a Polônia estima-se que havia, em 1939, 251 bibliotecas yiddish contendo 1.650.000 volumes (Fishman, 1981; Shavit, 1997). Para esse florescimento contribuíram o aumento da pobreza das famílias, o fechamento do acesso dos judeus às bibliotecas polonesas e o crescente envio de livros em proveniência de comunidades judaicas dos EUA, Canada e Argentina.

Durante a II Grande Guerra, todos esses acervos, juntamente com demais bens culturais judaicos, foram saqueados pelos nazistas. A maior parte dos acervos das bibliotecas comunitárias foi extinta juntamente com a destruição dos membros destas comunidades. Narrativas de sobreviventes dão testemunho dos esforços de bibliotecários, escritores e leitores para esconder livros e salvá-los da destruição. A ação da chamada "brigada de papel", que operou no interior do ghetto de Vilna durante a ocupação alemã, é uma destas experiências mais bem documentadas (Fishman, 2018; Sutzkever, 2013; Kruk, 2002). Estima-se que 1.5 milhão de livros e documentos judaicos roubados foram encontrados nos depósitos da Alemanha após a guerra, tendo sido 232.000 devolvidos à União Soviética e 54.000 encaminhados à nova sede do YIVO em Nova lorque ${ }^{13}$. O papel central desempenhado por este

\footnotetext{
${ }^{12}$ Yiddishland é o termo que alguns autores utilizam para designar o espaço cultural e linguístico das comunidades judaicas de lingua yiddish da Polonia, Lituânia, Bielorussia, Bessarábia e Ucrania antes da II Guerra. Cf. Le Yiddishland, une déterritorialisation révolutionnaire Alain Brossat, JeanMarc Izrine, Entretien avec Marco Candore, Chimères 2014/2, n. 83, p. 103-108.

${ }^{13}$ O YIVO é uma instituição criada em 1925 na cidade de Vilna, então Polônia, sob o nome de Yidisher Visnshaftlekher Institut (Instituto Científico Judaico), para ser uma referência em matéria de estudos da língua e literatura em língua yiddish. Fundado por um grupo de intelectuais de Vilna, Berlim e Nova York, as pesquisas do YIVO tinham por público-alvo as massas judaicas, cuja educação era seu objetivo primordial. Sediado hoje em Nova York, ele é responsável por grande parte do trabalho de reconstituição da memória cultural yiddish após a hecatombe perpetrada pelo nazismo (Acselrad, 2007).
} 
Instituto na geografia internacional do livro yiddish explica por que também no acervo constituído na Biblioteca Scholem Aleichem do Rio de Janeiro, de cujo histórico falaremos a seguir, encontram-se volumes marcados com o carimbo do "Clube dos Amigos do YIVO do Rio de Janeiro"14.

\title{
2. A militância pelo livro
}

As condições da criação da Biblioteca Scholem Aleichem, no Rio de Janeiro, foram assim relatadas por Saádio Lozinsky, um de seus fundadores, nascido em 1873 em Moscou, de onde partiu para a Holanda em 1909, chegando ao Brasil em 1914:

\begin{abstract}
"Os imigrantes judeus trouxeram consigo a sociabilidade europeia (...) Os judeus religiosos procuraram organizar um makóm kadôsh permanente onde pudessem rezar diariamente (...) O outro grupo, secular, procurou criar uma instituição cultural, um clube, onde pudesse se reunir e ler as obras de nossos escritores judeus, analisálas, promover debates a respeito, aguçar a mente, não deixar que ela se atrofiasse" (....) "Quando se trata do campo cultural, era preciso partir do "a"; e o "a" é o livro. Naqueles anos, 1914-1915, durante a Guerra Mundial, como se podia pensar em conseguir livros da Europa?" (...) "Mas os ativistas não desanimaram e, em uma salinha da Rua Visconde de Itaúna, começaram a formar uma biblioteca, coletando obras de doadores." (..) "O empreendimento ganhou vulto de ano para ano até que a biblioteca se tornou uma realidade sob a denominação de Biblioteca Israelita Scholem Aleichem". (1997, p. 194-196)
\end{abstract}

Para Lozinsky, um talmudista de inclinação socialista, "o interesse dos que frequentavam a Biblioteca girava em torno dos livros, jornais, semanários e mensários" (Lozinsky, 1997, p. 232). Entre seus fundadores, encontravam-se simpatizantes dos comunistas e do Bund, mas, a julgar por algumas obras do acervo, havia também leitores de traduções em yiddish de autores anarquistas como Reclus e de defensores da desobediência civil como Thoreau. Podemos falar do público da Biblioteca Scholem Aleichem como um "conjunto geracional", cujos laços se constituíram em torno a "conteúdos reais, sociais, intelectuais compartilhados num espaço caracterizado por um processo de instabilização e renovação" (Mannheim [1927], 1990, p. 59 e 67). Lozinsky não nega que, desde a fundação da Biblioteca, "ocorriam disputas entre os partidários de diferentes partidos ideológicos" (Lozinsky, 1997, p. 196). "As inclinações pessoais", pensava ele, "não deveriam, porém, passar da soleira da porta da Biblioteca, onde toda a atividade era de caráter estritamente cultural" (Lozinsky, 1997, p. 231-232).

Na publicação comemorativa do 40 aniversário da instituição, em 1955, é explícita a menção a disputas políticas internas ocorridas já antes de 1929, quando

\footnotetext{
${ }^{14}$ Em 1932, o YIVO enviou, de Vilna ao Rio de Janeiro, um emissário com o fim de ajudar a fundação de um comitê que se ocupasse de criar um arquivo da vida comunitária judaica no Brasil, na perspectiva de que cópias dos documentos fossem enviadas à sede do Instituto então na Europa (Malamud, 1988, p. 99). Provavelmente é esse comitê que esteve na origem do "Clube dos Amigos do YIVO do Rio de Janeiro".
} 
a convivência pacífica entre sionistas e não-sionistas ter-se-ia degradado (Farber, 1955). A diretoria era acusada, por um lado, de acolher mal os ativistas sionistas, enquanto os autodesignados progressistas recusavam a alegação segundo a qual, nos termos de seus oponentes, "se a biblioteca é judaica, ela tem que ser sionista" (Schenker, 1959, p. 171).

O acirramento do conflito deu-se por ocasião da visita de Albert Einstein ao Rio de Janeiro, em março de 1925. Segundo narrativa de dirigentes do grupo progressista, quando o representante da Biblioteca apresentou suas propostas ao comitê de recepção então montado, a presença deste delegado no referido comitê teria sido contestada pelos que alegavam que a instituição não passava "de uma meia dúzia de livros" e de que esses livros "não haviam sido comprados com dinheiro kosher" (Farber, 1955). Os membros sionistas da própria Biblioteca foram então criticados por não terem, ante tais ataques, se pronunciado em defesa da instituição ${ }^{15}$.

Ainda que a crise geral de 1929 tenha levado a Biblioteca ao endividamento e que muitas publicações estrangeiras tivessem deixado de chegar, as estatísticas da instituição registraram, entre 1922 e 1933, um total de 5.500 empréstimos de livros e a compra de 240 novos volumes. Há indicações de que, para além das dissensões no interior da comunidade judaica, dos efeitos da crise econômica e da ação repressiva do Estado, a prática da leitura tenha permanecido na diversidade de situações e formas de seu exercício.

Entre 1935 e 1945, pouco se pôde fazer sem a autorização dos gestores da censura prévia do Estado. A prisão de alguns diretores teria gerado temor em parte dos associados. Segundo o então dirigente Aaron Schenker, quando a diretoria conseguia permissão para a realização de algum evento, o público não comparecia: "a crise financeira era grave; mas quando a Biblioteca estava à beira de ser aniquilada, em 1936, surgiu um grupo de decididos, juntamente com o velho talmudista Lozinsky, que, praticamente, salvaram o tesouro cultural da Biblioteca" (Schenker, 1955) ${ }^{16}$. Após a libertação de seus dirigentes, com os

\footnotetext{
${ }^{15}$ As dissenções internas foram se intensificando até a eleição, em 1929, de uma nova diretoria, que deu a vitória à chapa progressista. Grupos descontentes fundaram o Clube Hatchia que deu lugar posteriormente à Biblioteca Bialik (Ribeiro, 2008). A historiadora Esther Kuperman (2003) sugere que existia já algum vínculo entre os então dirigentes da Biblioteca e o Partido Comunista Brasileiro pelo fato de, na sede da Biblioteca, ter sido realizada uma Conferência deste partido durante o Estado de Sítio de 1925 - um mês, portanto, antes da chegada de Einstein ao Rio de Janeiro. Em sua caracterização das correntes da imigração judaica da Europa do Leste para o Brasil, também Grin (1995) descreve os membros do "grupo dos judeus socialistas" como aqueles que intermediavam relações entre o Partido Comunista Brasileiro e a comunidade judaica.

${ }^{16}$ Assim relata o episódio o próprio Lozinsky, em suas memórias: "Quando, no período da ditadura de Vargas eu fui chamado a comparecer à Seção Política da Polícia, na qualidade de presidente da Biblioteca, em resposta às indagações das autoridades, eu declarei que, internamente, era eu o responsável e que ali não se lidava com assuntos políticos, mas que, externamente, isso não dizia respeito à instituição como tal e que a questão da vigilância era assunto da alçada dos órgãos governamentais" (1997, p. 232).
} 
problemas financeiros sanados, e com a redemocratização do país, as realizações culturais voltaram a se multiplicar ${ }^{17}$.

Chama a atenção o fato de que, mesmo na fala destes ativistas representantes do campo progressista, encontram-se traços de um vocabulário de origem religiosa como exemplificado a seguir: "com que sagrada emoção se tomava um livro emprestado nas primeiras bibliotecas do shtetl", (Morgenstern, 1960, p. 28); ou então: "com a literatura yiddish, o livro tornou-se santificado" e "todo livro recémpublicado era como um Yom-Tov" - uma festa religiosa (Schenker, 1959, p. 168).

O próprio Lozinsky, um dos fundadores da Biblioteca que se autointitulava "socialista religioso", pertenceu à geração que sucedeu imediatamente à de Morris Winchevsky, um dos pioneiros da literatura socialista judaica, que, na década de 1870, encontrava-se estudando na escola rabínica de Vilna, assim como Abraham Cahan, um dos mais famosos jornalistas socialistas judeus dos EUA, que, no início do século $X X$, conectava sua experiência religiosa pregressa à sua nova identidade política socialista, relatando o modo como "tocou com as mãos seu primeiro panfleto como a um objeto sagrado" (Sorin, 1985, p. 29). Cahan acreditava que as tradições estavam incorporadas ao imaginário judaico, inclusive de ateus como ele, o que explicaria porque, na passagem do século XIX para o século XX, a militância judaica do campo socialista "constantemente evocasse referências bíblicas e aforismas talmúdicos em seu discurso" (Sorin, 1985, p. 90). Tal interpretação estava presente já na fala de Aaron Liberman, o virtual fundador do socialismo judaico na Inglaterra, que, em 1875, arguia que as antigas estruturas judaicas evocavam o anarquismo e que os laços entre os judeus através do mundo expressavam seu internacionalismo (Frankel, 1981, p. 33, apud Sorin, 1985, p. $29)^{18}$. Não devemos desconsiderar, a este propósito, que diferentes valores e lógicas sociais se cruzam correntemente na constituição das pessoas: entre ativistas e leitores poderíamos certamente encontrar um leque de possiblidades, indo da

17 O relatório anual publicado em 1946 (Yiddishe Folks Bibliotekh, 1946, p. 16), registrou a aquisição, naquele ano, de 4.711 livros em yiddish, 487 em português, 284 em hebraico e 51 em russo, além de 212 livros infantis. Em 1955, o boletim comemorativo dos 40 anos da Biblioteca estimava em 10.000 o número de livros em yiddish contidos em seu acervo (Glazman, 1955).

${ }^{18}$ Em seu livro Redenção e Utopia, Michel Löwy afirma que "Max Weber foi provavelmente um dos primeiros a formular a hipótese do caráter potencialmente revolucionário da tradição religiosa do judaísmo antigo" (Lowy, 1989, p. 19). Lowy destaca, ademais, que "muitos historiadores julgam encontrar nas convicções socialistas e revolucionárias [de um certo número de] intelectuais russos a expressão secularizada do messianismo, a manifestação, sob uma forma ateia e materialista, de atitudes mentais herdadas de vários milênios de tradição religiosa" (1989, p. 43). Ele acredita, porém, que a Haskalá - movimento de abertura do mundo judeu à cultura racionalista e ao Iluminismo iniciado no final do século XVIII - teve traços distintos na Europa do Leste e na Alemanha. "Enquanto no Oeste, esse movimento aspirava à confessionalização, no Leste europeu, ele visava a secularização": "era preciso primeiro emancipar-se da religião, tornar-se ateu ou 'esclarecido', para poder aceder ao mundo 'externo' das ideias revolucionárias" (1989, p. 45). Nesse sentido, a perspectiva de Saádio Lozinsky, embora originário da Rússia, parece, de algum modo, ecoar o espírito do messianismo revolucionário de intelectuais judeus alemães como os estudados por Löwy. 
simples fusão entre crença e utopia até o uso estratégico de um vocabulário que atingisse parcelas mais amplas do público judaico.

Fato é que na rapidez com que se deram os processos de laicização nas comunidades judaicas da Europa do Leste, acompanhados como foram pela criação de bibliotecas em yiddish e pela disseminação de práticas coletivas de leitura, não é de se estranhar que, mesmo no âmbito da cultura secular emergente, tenham permanecido traços de um vocabulário religioso ${ }^{19}$. Este último foi, por alguns e em certas situações, transposto para novos objetos e projetos, refletindo um processo de "sacralização da cultura" (Kaufman, 2003, p. 185) e confirmando o que assinalara Ertel (2003, p. 44), de que, ao longo do processo de modernização, "todo movimento político no meio judaico assumiu o caráter de uma ecclesia militans", mesmo quando ateia ${ }^{20}$.

Ao discutir as semelhanças e diferenças entre a exegese bíblica e a literatura, Philippe Zard sustenta que a literatura se diferencia por se colocar fora do perímetro da moral, das normas sociais e, por certo, da religião. É por isso que o judaísmo teria, segundo Zard, uma relação ambivalente com a literatura (o livro teria uma relação ambivalente com os livros), posto que é próprio da literatura "assumir riscos com relação às certezas e ao dogma" 21 .

Como espaço de sociabilidade coletivamente construído, a reunião dos livros nas bibliotecas em língua yiddish resultava do encontro de diversos "espíritos colecionistas", cujos acervos foram, ao longo do tempo, convergindo para um mesmo ponto. Referindo-se a colecionadores de livros, Walter Benjamin sugere que seus acervos encerram uma "tensão dialética entre ordem e desordem". Na medida em que "a aquisição de um livro velho representa seu renascimento", o impulso dos colecionadores de livros - como, supomos, o de ativistas de bibliotecas - é o de "renovar o mundo velho", fazendo com que as bibliotecas acabem contendo, ao mesmo tempo, "o inescrutável e o inconfundível" (Benjamin, 1987, p. 229-231); e que juntamente aos livros, toda biblioteca acabe abrigando objetos situados em regiões fronteiriças do que Benjamin chama de suas "orlas prismáticas"

\footnotetext{
${ }^{19}$ Assim descreveu Hidiroglou (2006, p. 231) o ambiente das bibliotecas yiddish em Paris no período entreguerras: "o público destas bibliotecas era formado de operários e lojistas, 'gente pobre' para quem o livro era sagrado. Várias pessoas evocaram a atmosfera religiosa, sagrada que reinava nas salas de leitura".

${ }^{20}$ Quando, em 1942, milhares de livros saqueados pelos nazistas foram enviados à Alemanha, Herman Kruk, o então responsável pela biblioteca do ghetto de Vilna, declarou aquela data como de contrição pública (Fishman, 2018). Não é difícil relacionar, de algum modo, a sacralização dos textos literários aos procedimentos da tradição religiosa da gueniza (héb.: הזינג "[local de guarda]"). Obras redigidas em hebraico, quando tornadas inutilizáveis, eram guardadas, à espera de serem enterradas em um cemitério. A sacralização da palavra escrita podia estender-se a documentos profanos redigidos com caracteres hebraicos em outros idiomas, como é o caso do yiddish. Cf. Solomon Schechter, Elkan N. Adler. Genizah. In: <http://www.jewishencyclopedia.com/articles/6582-genizah> e <https:// fracademic.com/dic.nsf/frwiki/694981 >. Acessos em 12.12.2019.

${ }^{21}$ Philippe Zard. Littérature et judaïsme, Entrevista, <https://www.franceculture.fr/emissions/ talmudiques/mais-quest-ce-que-donc-un-cochon>, 03/06/2018. Acesso em: 04.09.2019.
} 
(1987, p. 234). No caso da Biblioteca Scholem Aleichem, a observação de tais "prismas" permite, a título de exemplo, encontrar, em meio às páginas dos livros, uma diversidade de folhetos, prospectos e recortes de jornal, assim como velhas provas de geografia de escolas judaicas, manuscritos de discursos em yiddish preparados para eventos comemorativos, boletos de pagamento de mensalidades de instituições judaicas e todo tipo de marcadores improvisados de páginas traços da vida cotidiana que se misturavam ao imaginário dos textos pelos quais trafegavam seus leitores.

\section{Leitores-viajantes, deslocamentos e continuidades}

Em sua maioria, os povos constrangidos a deixar seus territórios de origem veem-se submetidos a relações de força particularmente desfavoráveis. Seu êxodo pressupõe a possibilidade de se implantarem em outros lugares, e, sobretudo, de serem capazes de se adaptar a novos contextos, desenvolvendo atividades e contatos que lhes permitam se inserir, ainda que de forma dispersa, nas diferentes sociedades de acolhida (Lacoste, 1989, p. 9).

O engajamento político no Yiddishland foi visto como uma longa viagem: "é preciso um atlas na mão para seguir suas peregrinações, a sucessão de seus combates" (Brossat, Klingsberg, 1983, p. 16). Não por acaso a noção de Atlas foi associada, por Didi Huberman, à experiência da constituição de uma biblioteca singular, a de Warburg 22, como espaço de pensamento resultante da "montagem dinâmica de heterogeneidades", da configuração de uma constelação de arquivos coordenados através de percursos em "zigzag mais do que em uma linha reta" (Georges Didi-Huberman, 2011, p. 280 apud Martin, 2014). Tais zigzags foram percorridos também pelos livros migrantes, assim como por seus leitores. Repercutindo os trajetos migratórios dos leitores, os livros que compuseram seus "atlas/bibliotecas" expressam o mundo a partir de um olhar particular - "das margens", pois não remetendo ao judaísmo religioso e tradicional, nem ao sionismo, o olhar destes sujeitos exprime o que Traverso considerou o "privilégio epistemológico do exílio"23.

${ }^{22}$ A biblioteca do historiador da arte Amy Warburg, fruto de uma coleção iniciada em 1901, ficou conhecida por sua forma mutante de organização baseada em relações de justaposição momentânea dos volumes, de vizinhança apropriada e adaptada a um instante de pensamento e não em relações temáticas ou cronológicas. Zarnoveanu (2012, p. 5) sustenta que entre a Biblioteca de Warburg e seu igualmente original Atlas de imagens havia em comum a busca de um mesmo princípio catalizador que buscava aproximar a materialidade do livro e da imagem à ideia representada.

${ }^{23}$ Traverso assinala que a observação da história na perspectiva dos intelectuais judeus exilados no entreguerras representa uma vantagem, pois permite estudar os grandes problemas do mundo contemporâneo daquela época a partir das margens: "Essa perspectiva desde as margens tem seus privilégios epistemológicos: é um olhar que pode fazer abstração, que escapa às categorias analíticas conformistas que são as que se constroem a partir de um ponto de vista dominante" (...) "Olham o mundo a partir de um observatório muito particular das margens, o que lhes permite ver coisas que outros não veem. Esse é o privilégio epistemológico do exilio" (Traverso, 2006, p. 88). 
Educados segundo a tradição judaica da Europa do Leste ou da Zona de Residência na Rússia, os imigrantes judeus da primeira metade do século XX haviam descoberto, ao longo de sua adolescência, a literatura profana e, com ela, o mundo exterior. Esta viagem pelo mundo da literatura foi, para muitos deles, acompanhada de uma viagem para fora dos shtetls e de seus países de origem. Tornaram-se, assim, leitores-viajantes, tal como De Certeau pretende que o sejam metaforicamente todos os leitores - os que "circulam nas terras do próximo", "nômades que caçam furtivamente nos campos que não escreveram" (De Certeau, 2012, p. 141). Em seu romance sobre o livro yiddish, Peter Manseau relata experiências segundo as quais, mal desembarcado do Velho Mundo, o imigrante judeu sonhava ter uma casa com um cômodo onde conservar seus livros. Caso a casa não fosse suficientemente grande, os livros teriam de ser sacrificados. Guardados por quem tinha espaço para acolhê-los, formavam bibliotecas que "continham os sonhos de alguém" (Manseau, 2008, p. 318).

Este tipo de continuidade no tempo se estabelece também no espaço, posto que a leitura é o "produto itinerante de uma experiência material e concreta" em que os "leitores-viajantes" leem a si próprios, ao mesmo tempo em que, expostos às ideias contidas nos livros, são atraídos pelos desafios da alteridade (Freijomil, 2009). Pelos livros, se vai, se vem e se passa (De Certeau, 1969, p. 6). A própria escrita pode ser itinerante: "sempre em viagem, é em hotéis e estações ferroviárias que escreveram Proust, Wittgenstein, Nabokov" (Steiner, Spire, 2000, p. 27). No caso da literatura yiddish, em paralelo à própria onda migratória, é visível a importância do deslocamento espacial de escritores, assim como de seus personagens (ver quadro abaixo). O escritor Scholem Aleichem escreveu romances ferroviários e epistolares. Entre seus personagens encontramos caixeiros viajantes, migrantes, missivistas e errantes. Em sua obra, o deslocamento não é apenas um tema, mas um modo de considerar o mundo, ilustrando o fato que, por sua capacidade de absorver influências dos contextos vividos, o yiddish teria o feitio de "uma língua-passaporte" (Guinsburg, 1996, p. 35-36), que preservou a si própria numa dialética em que o fechamento imposto a seus locutores resultou, paradoxalmente, em abertura para o mundo.

As ondas da migração judaica abriram também espaço para o surgimento de escritores viajantes que desenvolveram uma linguagem própria aos relatos de viagem. Os textos que narram as condições de implantação dos imigrantes em seus locais de destino interessaram tanto aos que, na Europa, pensavam em emigrar, como àqueles que não viram na imigração uma solução. Na visão de alguns dos escritores viajantes, o futuro judaico seria diaspórico e etnonacional, dada a expectativa de afirmar-se uma cultura nacional yiddish tanto na Europa como nos países de emigração (Kalczewiak, 2017, p. 132). Tendo visitado a Argentina e o Brasil em 1914 e 1925, o escritor em língua yiddish Peretz Hirschbein assim descreve a redução das distâncias através da literatura: 
"graças ao livro yiddish, os oceanos não nos separam mais. Há uma unidade intelectual que nos conecta seja onde estivermos"24. "Você viaja semanas a fio por terra e mar; alcança as praias de um país remoto e sua gente vem encontrá-lo. As semanas de distância entre você e eles subitamente se estreita. Você começa a pensar que a distância não é tão grande assim, mas que apenas o capitão escolheu o caminho errado, girando em torno ao mesmo lugar o tempo todo." ${ }^{25}$

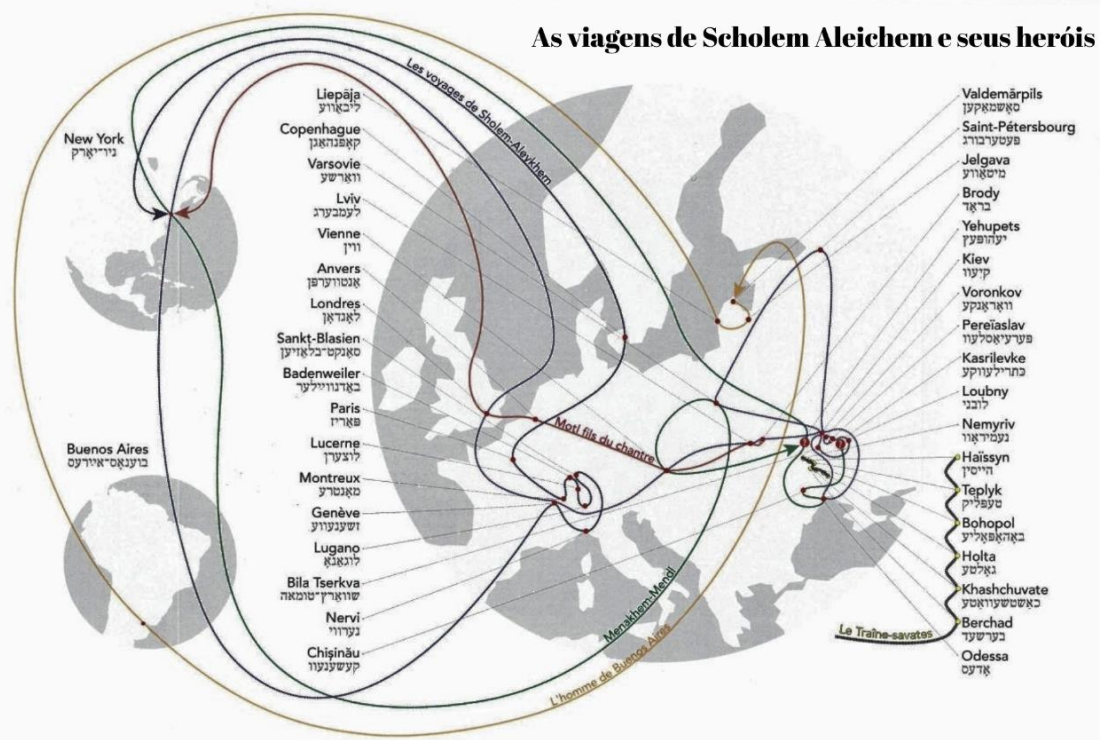

Fonte: Sholem-Aleykhem, l'écrivain des comédies humaines. Maison de la culture yiddish - Bibliothèque Medem, Paris, 2016, p. 3.

Mobilidade e continuidade - no tempo e no espaço - contribuíram para constituir a geografia e a "geologia" das bibliotecas em língua yiddish. Emblemático da mobilidade de seus leitores, como dos escritores e de seus textos, é o caso do jornalista Joseph Halevi, responsável pelo primeiro órgão de imprensa yiddish no Brasil, o periódico "Di Menscheit" (A Humanidade), publicado em Porto Alegre entre 1915 e 1920. Ex-correspondente do jornal polonês Hatzefira na Argentina, Halevi levava uma vida de eremita, costumando se deslocar da Argentina para o Brasil a pé (Falbel, 1984, p. 155) ${ }^{26}$. Essa condição de nômade intelectual exprimia

${ }^{24}$ P. Hirschbein, Ikh Kum On Kein Buenos Ayres, Arquivos YIVO, s.d., Peretz Hirschbein Papers, apud Kalczewiak, 2017, p. 129.

${ }^{25}$ P. Hirschbein, Fun vayte lender, Argentine, Brazil, yuni november 1914, New York, Ferlag Tog, 1916, p. 13 apud Kalczewiak, 2017, p. 134. Conhecido como um escritor viajante, Hirschbein estava a bordo de um navio britânico quando eclodiu a I Grande Guerra. Tendo este navio sido atacado por um cruzador alemão, o escritor, após ser detido por alguns dias, conseguiu chegar ao Brasil e, em seguida, a Nova York. <http://yleksikon.blogspot.com/2016/03/perets-hirshbeynperetz-hirschbein.html>.

${ }^{26}$ A prática de fundar bibliotecas acompanhou o deslocamento espacial de escritores e jornalistas, inclusive entre Argentina e Brasil, como foi também o caso de Leib Malach, que, chegado à 
algo que Siegfried Kracauer entendeu ser próprio a uma exterritorialidade geográfica e existencial engendrada pelo exílio (Traverso, 2019, p. 194-195). A partir de Georg Simmel, Kracauer construiu a ideia de exterritorialidade como categoria essencial da modernidade judaica. Teria havido, primeiramente, a exterritorialidade com respeito à tradição, a um universo religioso que foi, por séculos, o eixo central do mundo judaico e que implodiu após a emancipação no seio do mundo secularizado. Houve, em seguida, a exterritorialidade do judeu com relação ao sistema de Estadosnação, a forma política da Europa moderna. Por fim, uma exterritorialidade com relação ao próprio mundo, no qual certos sujeitos não teriam mais o direito de viver e para os quais não haveria mais lugar (Traverso, 2019, p. 182). Os leitores-viajantes das bibliotecas yiddish tentaram preencher este quase-vazio da exterritorialidade através de uma viagem literária entre mundos, entre presente e passado, suspensos entre os dois, ou, nos termos de Kracauer (Traverso, 2019, p. 196 e 202), buscando, ao mesmo tempo, salvar o passado e decifrar o presente.

\section{Considerações finais}

Com o processo migratório iniciado em fins do século XIX, o território ocupado pelos falantes da língua yiddish na Europa do Leste começou a ser dissociado da língua que o designava. Após o Holocausto, este território, antes por ela nomeado, tornou-se fantasmático (Ertel, 2003, p. 11). Nos diferentes continentes e países de acolhida dos imigrantes, foi nos livros e nas bibliotecas que seus espaços de vida foram, em grande parte, reconstituídos. A língua desempenhou, consequentemente, o papel de um espaço geográfico disperso, uma rede cujas malhas foram sendo formadas por palavras. Em ausência de um território definido, foi em direção a esta língua que diferentes correntes culturais e políticas confluíram (Ertel, 2003, p. 50). A memória nela contida não teria, porém, representado apenas um instrumento para a exploração do passado, mas o próprio meio onde se deu sua vivência, assim "como o solo é o meio no qual as antigas cidades estão soterradas" (Benjamin, 1987, p. 239). Tal memória remete, portanto, antes a uma cosmogonia - a um "passado" que integra o cosmo da profundeza do ser - do que a uma cronologia (Vernant, 1973, p. 112-113).

Sobre a relação íntima entre leitores e livros, Walter Benjamin evoca a biblioteca como morada que tem os livros como tijolos (1987, p. 235). Esta morada pode conter tanto camadas geológicas e fissuras, como temporalidades e deslocamentos. Toda obra literária ou filosófica, como a Divina Comédia e a Ética de Spinoza, afirma Benjamin (1987, p. 228-229), tem um destino, como o têm também os próprios exemplares destas obras. Os livros migrantes, por sua parte, têm por destino tornarem-se, ao mesmo tempo, objetos-memória, objetos-sujeitos e objetos-ponte,

Argentina em 1922, proveniente da Polônia, ajudou a fundar bibliotecas em Cachoeira e Santa Maria, áreas rurais do Rio Grande do Sul onde havia colônias judaicas criadas pela Jewish Colonization Association - ICA (Falbel, 1984, p. 165). 
mediadores no processo de inscrição dos migrantes em seus novos espaços de vida. Estes objetos devem tanto ao passado como ao presente, à grande história como ao mundo doméstico, carregados como são de sentidos e afetos julgados indispensáveis e dos quais os migrantes não conseguem se separar. O caráter indefectível de sua presença seria para eles a garantia de continuidade de suas vidas. A despeito do desenraizamento territorial dos migrantes, estes objetos teriam, para estes sujeitos, o poder de atenuar a violência da ruptura entre o antes e o depois, acompanhando a transição e a reconstrução de seus laços sociais (Azria, 2016). Isto porque os objetos migrantes acompanham o exílio, povoam a terra de acolhida e singularizam o grupo em deslocamento. No caso dos livros, em particular, a capacidade dos membros do grupo reconstruírem seus mundos perdidos se apoia na memória das palavras que habitam estes mundos e que ninguém fora dele pode entender plenamente senão tendo à mão uma gramática sentimental própria. Esta capacidade se volta não só a evocar o passado, mas a revivê-lo com a força e a evidência de um presente não acabado. Como sublinha Finazzi-Agrè (2009, p. 222-227), usar e continuar usando uma mesma linguagem particular é a maneira de resistir a um tempo vertiginoso e trágico, de permanecer num lugar certo e próprio, no "espaço desmedido e cheio de ruinas que costumamos chamar de moderno".

\section{Referências bibliográficas}

ACSELRAD, Henri. De Vilna ao Rio de Janeiro: territórios da laicidade judaica. Estudos Históricos, Rio de Janeiro, n. 40, p. 136-153, julho-dezembro 2007.

APPADURAI, Arjun. A vida social das coisas. Niterói: EDUFF, 2008.

AZRIA, Regine. Entre lares et pénates: les objets de la diaspora. Diasporas, v. 27, p. 55-66, 2016.

BENJAMIN, Walter. Rua de Mão Única. Obras escolhidas II. São Paulo: Ed. Brasiliense, 1987.

BLAY, Eva. Alterman, Inquisição, inquisições: aspectos da participação dos judeus na vida sociopolítica brasileira nos anos 1930. Tempo Social, v. 1 n. 1, p. 105-130, 1989.

BROSSAT, Alain; IZRINE, Jean-Marc. Le Yiddishland, une déterritorialisation révolutionnaire, entrevista concedida a Marco Candore. Chimères, n. 83, p. 103108, 2014/2.

CHARTIER, Roger. Lecteurs et lectures à I'âge de la textualité électronique. In: ORIGGI, Gloria; ARIKHA, Noga (dir.). Text-e, Le Texte à I'heure d'internet. Paris: Ed. de la Bibliotèque publique d'information - Centre Pompidou, 2003, p. 17-30.

CHARTIER, Roger; BOURDIEU, Pierre. La lecture: une pratique culturelle. In: CHARTIER, Roger (org.). Pratiques de la lecture. Paris: Petite Bibliotèque Payot, 2003, p. 277-306.

DE CERTEAU, Michel. L'étranger ou I'union dans la différence. Paris: Desclée de Brouwer, 1969. 
DE CERTEAU, Michel. Uma operação de caça. In: DE CERTEAU, Michel. A Invenção do Quotidiano - Artes do fazer. Petrópolis: Ed. Vozes, 2012.

DECOL, René Daniel. Judeus no Brasil: explorando os dados censitários. Revista Brasileira de Ciências Sociais, v. 16, n. 46, p. 147-160, 2001.

DIDI-HUBERMAN, Georges. Atlas ou le gai savoir inquiet, L'œil de I'histoire, 3. Paris: Minuit, 2011.

ERTEL, Rachel. Brasier des mots. Paris: ed. Liana Levi, 2003.

FALBEL, Nachman. Estudos sobre a comunidade judaica no Brasil. São Paulo: Federação Israelita do Estado de São Paulo, 1984.

FARBER, Leizer. Di Bibliotek Scholem Aleichem in di yorn 1931-1935. Biuletin Iubloissgabe tzum 40-stn yortag fun der Yiddishe-Brazilianische Bibliotek Scholem Aleichem. Rio de Janeiro, p. 15-18, 1955.

FINAZZI-AGRÒ, Ettore. Posfácio a Natalia Guinzburg. In: GUINZBURG, Natalia. Léxico Familiar. São Paulo: Cosac Naify, 2009.

FISHMAN, David E. Os Homens que salvavam livros - a luta para proteger os tesouros judeus das mãos dos nazistas. São Paulo: ed. Vestígio, 2018.

FISHMAN, Joshua A. (ed.). Never Say Die! A Thousand Years of Yiddish in Jewish Life and Letters. The Hague, Paris e New York: Mouton, 1981.

FRANKEL, Jonathan. Prophecy and Politics: Socialism, Nationalism and the Russian Jews, 1862-1917. Cambridge: Cambridge University Press, 1981.

FREIJOMIL, Andrès G. Les pratiques de la lecture chez Michel de Certeau. Cahiers du Centre de Recherches Historiques, n. 44, 2009, p. 109-134.

GLAZMAN, M. Di Bibliotekh Scholem Aleichem - ir bicher Oitzer un ir historischer archiv. Biuletin lubl-oissgabe tzum 40-stn yortag fun der Yiddishe-Brazilianische Bibliotek Scholem Aleichem. Rio de Janeiro, p. 36-40, 1955.

GRIN, Mônica. Etnicidade e cultura política no Brasil. O caso dos imigrantes judeus do Leste Europeu. Revista Brasileira de Ciências Sociais, v. 10, n. 28, São Paulo, jun. 1995.

GUINSBURG, Jacó. Aventuras de uma língua errante - ensaios de literatura e teatro ídiche. São Paulo: Ed. Perspectiva, 1996.

HIDIROGLOU, Patricia. Le monde yiddish polonais et les bibliothèques dans l'entredeux guerres à Paris. À la recherche des racines de la civilisation européenne, Annales. Varsovie-Paris: Centre scientifique de l'Académie Polonaise, 2006, p. 214-233. Disponível em: <https://docplayer.fr/14801357-Le-monde-yiddish-polonais-et-sesbibliotheques-dans-I-entre-deux-guerres-a-paris.html>. Acesso em: 09.08.2019.

JONES, Faith. The Vancouver Peretz Institute Yiddish Library: the social history of a jewish community library. School of Library, Archival and Information Studies. Vancouver: University of British Columbia, 1999.

KALCZEWIAK, Marciusz. Jewish Polacos, Argentina and the Yiddishland: negotiating transnational identities, 1914-1939. Tese de Doutorado em Filosofia, Justus-Liebieg Universitat, Berlim, 2017.

KAUfMAN, Tania N. Passos Perdidos, História Recuperada: a presença judaica em Pernambuco. 3a ed. Recife: Ed. Ensol, 2003. 
KRUK, Herman. The Last Days of the Jerusalem of Lithuania: Chronicles from the Vilna Ghetto and the Camps 1939-44. Editado por Benjamin Harshav. Yale: Yale Universiy Press, 2002.

KUPERMAN, Esther. ASA - Gênese e trajetória da esquerda judaica não sionista carioca. Boletim ASA, n. 84, set.out. 2003.

LACOSTE, Yves. Géopolitique des diásporas. Hérodote, n. 53, p. 3-12, 2o Trimestre 1989. LESSER, Jeffrey Howard. O Brasil e a questão judaica: imigração, diplomacia e preconceito. Rio de Janeiro: Imago, 1995.

LÖWY, Michel. Redenção e utopia - o judaísmo libertário na Europa Central. São Paulo: Cia. das Letras, 1989.

LOZINSKY, Saádio. Memórias da Imigração - reminiscências e reflexões. Rio de Janeiro: Ed. HAI/Garamond, 1997.

MAISON DE LA CULTURE YIDDISH. Sholem-Aleykhem, l'écrivain des comédies humaines. Paris: Bibliothèque Medem, 2016.

MALAMUD, Samuel. Recordando a Praça Onze. Rio de Janeiro: Livraria Kosmos ed.,1988.

MANDELSTAM, Ossip. La Bibliothèque. In: MANDELSTAM, Ossip. Le Bruit du temps. Paris: Christian Bougois Ed., 2006.

MANNHEIM, Karl. Le Problème des générations [1927]. Trad. Gérard Mauger et Nia Perivolaropoulou. Paris: Nathan, 1990.

MANSEAU, Peter. Chansons pour la fille du boucher. Paris: Christian Bourgois Editeurs, 2008.

MARTIN, Serge. Fabriquer des atlas. Le mémoire? Un «atlas», c'est-à-dire «un montage d'hétérogénéités». 2014. Disponível em: <https://arlap.hypotheses.org/2835>. Acesso em: 07.02.2020.

MORGENSTERN, Pinie. Der Hoidesh farn yiddish buch (O mês do livro yiddish). Funker, IKUF, Rio de Janeiro, p. 28-30, dezembro de 1960.

PINSKY, Jaime. Origens do nacionalismo judaico. São Paulo: ed. Ática, 1997.

POLYANSKI, Motl. A kleyn shtetele in der groyser velt. Sovetish heymland, n. 7, p. 110133, 1978 (Uma pequena cidade neste enorme mundo, trad. Isaac Acselrad, mimeo). RIBEIRO, Paula. Cultura, memória e vida urbana: judeus na Praça Onze, no Rio de Janeiro (1920-1980). Tese de Doutorado em História Social, PUC-SP, São Paulo, 2008.

ROTH, Joseph. A cidadezinha judaica. In: ROTH, Joseph. Judeus Errantes. Trad. Simone Pereira Gonçalves. Belo Horizonte: ed. Âyné, 2016.

SAID, Edward. Reflexões sobre o exílio e outros ensaios. São Paulo: Cia das Letras, 2003.

SCHECHTER, Slomon; ADLER, Elkan N. Genizah. Disponível em: <http://www. jewishencyclopedia.com/articles/6582-genizah>.

SCHENKER, Aaron. 40 yor existentz fun der Bibliotekh Scholem Aleichem. Biuletin lubl-oissgabe tzum 40-stn yortag fun der Yiddishe-Brazilianische Bibliotek Scholem Aleichem. Rio de Janeiro, p. 10-14, 1955. 
SCHENKER, Aaron. Hoidesh fun yiddishn buch. In: SCHENKER, Aaron. Vort um Tat. Rio de Janeiro: IKUF, 1959, p. 168-170.

SHAVIT, David. Hunger for the Printed Word: Books and Libraries in the Jewish Ghettos of Nazi-Occupied Europe. Jefferson, NC and London: McFarland, 1997.

SINGER, Isaac B. Le Yiddish. L'Arc, n. 93, p. 17-23, 1984.

SORIN, Gerald. The Prophetic Minority - american jewish immigrants radicals, 18801920. Bloomington: Indiana University Press, 1985.

STEINER, George. Le Silence des livres. Paris: Arléa, 2007.

STEINER, George; SPIRE, Antoine. Barbarie de l'ignorance. La Tour-d'Aigues: Ed. de L'Aube, 2000.

SUTZKEVER, Avrom. Le Ghetto de Wilno - 1941-1944. Paris: Denoel \& D'ailleurs, 2013.

SVASEK, Maruška (ed.). Moving Subjects, Moving Objects: Transnationalism, Cultural Production and Emotions. Serie Material Mediations: People and Things in a World of Movement. New York: Berghahn, 2014.

TRAVERSO, Enzo. La pensée dispersée - figures de l'exil juif. Paris: Lignes, 2019.

TRAVERSO, Enzo. Entrevista. Politicas de memoria, n. 6/7, Buenos Aires, p. 97-101, verano 2006-2007.

VERNANT, Jean-Pierre. Aspectos míticos da memória e do tempo. In: VERNANT, JeanPierre. Mito e Pensamento entre os gregos. São Paulo: Difel/Edusp, 1973, p. 107-147.

WEISER, Kalman; FOGEL, Joshua A. (eds.). Czernowitz at 100 - the first yiddish language conference in historical perspective. Lanham: Lexington Books, 2010.

YIDDISHE FOLKS BIBLIOTEKH SCHOLEM ALEICHEM. Yerlicher Baricht. Rio de Janeiro, 1946.

ZARNOVEANU, Diana Elena. L'image entre réflexion et représentation. Aby Warburg et Walter Benjamin. Thèse en Littérature Comparée, Université de Montréal, 2012. 